\title{
LA COMUNIDAD EUROPEA DEL CARBÓN Y DEL ACERO. UN EXITOSO Y AÚN INACABADO EXPERIMENTO INSTITUCIONAL
}

\section{Eduardo TORRES ESPINOSA*}

Resumen: La Comunidad Europea del Carbón y del Acero es el origen programático e institucional de la actual Unión Europea. Este hecho, sin embargo, ha perdido paulatinamente fuerza como resultado del dinamismo del proceso de integración. Este artículo busca llamar la atención sobre la inusual persistencia en el tiempo de los objetivos y estrategias establecidos por el Plan Schuman. Su argumento central es que el novedoso diseño institucional supranacional adoptado por el Tratado de París en 1952 resultó ser la mejor solución para resolver un añejo problema de inestabilidad política por la vía de la integración económica gradual. La principal conclusión es que, aunque muchos eventos han ocurrido en Europa, la arquitectura institucional actual de la Unión Europea sigue siendo esencialmente la misma que la concebida hace ya más de medio siglo.

ABSTRACT: The European Community of Coal and Steel is the programmatic and institutional origin of the present European Union. This fact, nevertheless, has lost gradually force as a result of the dynamism of the integration process. This article looks to draw attention on the unusual persistence in time of the objectives and strategies established by the Schuman Plan. Its central argument is that the novel supranational institutional-design adopted by the Treaty of Paris in 1952 turned out to be the best solution to solve an aged problem of political instability by the route of gradual economic integration. The main conclusion is that, although many events have occurred in Europe, the European Union's current institutional architecture is essentially the same as that conceived more than half a century ago.

RÉSUMÉ: La Communauté Européenne du Charbon et de l'Acier se trouve à l'origine de l'actuelle Union Européenne, elle lui a donné son dessein programmatique e institutionnel. Cependant, ce fait a perdu, peu á peu, sa force par le propre dynamisme du processus d'intégration. Cet article met l'accent á propos de l'étrange persistance au long du temps, de l'objectif et des stratégies que le Plan Schuman a établis. Son idée central c'est que l'innovateur dessein institutionnel supranational que le Traité de Paris a adopté en 1952, reste la meilleure solution pour résoudre le vieux problème de manque de stabilité politique, par la voie d'une intégration économique progressive. L'une des principales conclusions, c'est que malgré les nombreux événements qui se sont succédés en Europe, l'architecture institutionnelle d'aujourd'hui de l'Union Européenne est substantiellement la même que celle conçue il y a déjà un demi siècle.

* Maestro en políticas públicas por la Universidad de Exeter, Inglaterra; doctor en gobierno por la London School of Economics; profesor en la FES Acatlán de la UNAM y miembro del SNI. El autor agradece a la UNAM, vía la DGAPA, su apoyo para disfrutar de una estancia sabática en el extranjero; asimismo, a diversas bibliotecas de la Universidad de Texas, en Austin, por facilitarme la información que utilicé en la elaboración de este artículo. 
No habrá paz en Europa si los Estados deciden reestablecerse sobre la base de la soberanía nacional... Los países europeos son demasiado pequeños... Para disfrutar de la prosperidad y el progreso social... deben formar... una 'Entidad europea' que los haga una sola unidad económica.

Monnet, Jean, Memoirs, Londres, Collins, 1978, p. 222.

If the new Community and its organs can come into being and work, it seems to the writer likely that it either must lead to new antagonisms or, as we all hope, to a much more intimate union of this part of Europe.

KunZ, Josef L., "Supra-National Organs", The American Journal of International Law, vol. 46, núm. 4, 1952, p. 698.

Sumario: I. Introducción. II. El Plan Schuman. Contexto internacional y regional. III. Dimensión político-institucional de la Comunidad Europea del Carbón y del Acero. IV. Primeras acciones y logros de la Comunidad, 1952-1957. V. De la Comunidad Europea del Carbón y del Acero a la Unión Europea. VI. Los debates actuales sobre la Unión Europea a la luz de sus primeras interpretaciones. VII. Conclusiones.

\section{INTRODUCCIÓN}

Existe acuerdo en que la creación de la Comunidad Europea del Carbón y del Acero en 1951 detonó el proceso europeo de integración. Sin embargo, la literatura actual sobre el Tratado constitutivo de la primera Comunidad y sobre sus primeros años de vida es muy escasa. Este hecho es relevante si se considera que el conocimiento de los orígenes de toda institución es imprescindible para entender su presente. En buena medida, este silencio podría deberse al inusual dinamismo que ha mostrado dicho proceso. Y es que desde la Declaración Schuman, Europa Occidental ha experimentado una transición económica y política que parece no tener fin. Este particular contexto parece justificar que la mayoría de los estudios europeos estén más ocupados en explicar los acontecimientos del día a día que hechos que parecerían ya muy lejanos y cada vez menos vinculados al presente. 
A diferencia, en este artículo se intenta demostrar que existe una relación más directa de lo que generalmente se piensa entre el plan que inspiró la constitución de la Comunidad Europea del Carbón y del Acero, y la dirección que el proceso de integración ha seguido desde entonces. Desde esta perspectiva, el caso europeo emerge como la inusual historia de una teoría que ha sido fiel y exitosamente llevada a la práctica. Nuestra hipótesis es que ello no hubiera sido posible sin la guía del innovador y persistente andamiaje institucional supranacional con que se dotó a la primera Comunidad. Su estudio se hará desde la óptica del nuevo institucionalismo, enfoque teórico que enfatiza el papel de las instituciones en la vida política. ${ }^{1}$

La naturaleza del objeto de estudio demanda la utilización tanto del método sincrónico como del diacrónico. ${ }^{2}$ El primero —a través de la congelación artificial de episodios - nos permitirá analizar detalladamente las primeras "fotografías" de la Comunidad bajo escrutinio. A ello obedece el uso extensivo de fuentes primarias y secundarias de información disponibles en ese tiempo. Frente al gran dinamismo del proceso a explorar, el segundo método hará posible contrastar esas imágenes con su "video", con el propósito de identificar los principales cambios y su dirección a través del tiempo. Se considera que esta estrategia metodológica puede ayudar a entender la situación actual de la Unión Europea, así como vislumbrar su futuro.

Además de esta introducción y las conclusiones, el artículo consta de cinco secciones. En las tres primeras se presenta una visión diacrónica de la Comunidad, objeto de estudio. Luego de presentar un breve marco contextual, se analiza su estructura institucional y los primeros resultados de su acción. En la siguiente sección se lleva a cabo el ejercicio diacrónico y se llama la atención sobre la continuidad del proceso. En la última sección, se contrastan las primeras interpretaciones del fenómeno europeo con los debates más recientes sobre el mismo tema, para demostrar que muchas de ellas, aunque olvidadas, no han perdido actualidad.

1 March, James G. y Olsen, Johan P., Rediscovering Institutions, Nueva York, The Free Press, 1989; Hay, Colin, Political Analysis: A Critical Introduction, Nueva York, Palgrave, 2002, pp. 35-42; Peters, Guy B., El nuevo institucionalismo: Teoría institucional en ciencia política, Barcelona, Gedisa, 2003.

2 Una explicación general de estos métodos puede encontrarse en Hay, Colin, op. cit., nota 1, pp. 60-65. 


\section{El Plan SCHUMAN. CONTEXTO INTERNACIONAL Y REGIONAL}

Por décadas, la zona carbonífera del Ruhr constituyó un tema medular en las relaciones entre Francia y Alemania, así como una fuente de tensión e inestabilidad regional. La Guerra Franco-Prusiana provocó la cesión de una parte de Lorraine al Imperio Alemán en 1871. Con ello, "los ricos yacimientos de hierro de la Cuenca de Briey" fueron divididos. ${ }^{3}$ A partir de entonces, Lorraine contribuyó con sus ricos yacimientos minerales a la consolidación del complejo siderúrgico del Ruhr y, por tanto, a la rápida expansión industrial y militar alemana. La Cuenca del Saar jugó el mismo papel. El Tratado de Versalles (1919) dio autoridad sobre esta última a la Liga de las Naciones por quince años, y devolvió Lorraine a Francia. No obstante, los franceses se percataron muy pronto de que el Ruhr podía modernizarse y prosperar sin Lorraine, pero que esta última no podía sobrevivir sin el carbón de la primera. ${ }^{4}$

El fin de la Segunda Guerra Mundial trajo de nuevo el asunto del Ruhr a la mesa de negociaciones. ${ }^{5}$ Con justa razón, los aliados atribuyeron al carbón alemán el haber permitido el poderío militar de Hitler. ${ }^{6}$ Así, en su mira se encontraba el Ruhr y la producción de acero dominada por el emporio Vereinigte Stahlwerke. Un factor decisivo en la forma como que se resolvió la lucha por su control fue la partición de Alemania en "zonas de ocupación" y el acuerdo entre los Estados Unidos y el Reino Unido de 1944, por el cual dichos países decidieron que el Ruhr quedara ubicado dentro de la zona británica. En respuesta, Francia y luego la Unión Soviética demandaron, con un mayor énfasis, la "internacionaliza-

3 Sethur, Frederick, "The Schuman Plan and Ruhr coal", Political Science Quarterly, vol. 67, núm. 4, 1952, p. 503.

4 Gillingham, John, J., Coal, Steel and Rebirth of Europe, 1945-1955: The Germans and the French from Ruhr conflict to economic community, Cambridge, Cambridge University Press, 1991.

5 Se ha argumentado que el origen de la Segunda Guerra Mundial está vinculado con la forma en que el Tratado de Versalles intentó resolver el conflicto del Ruhr. Véase la obra de Schmidt, Royal J., Versailles and the Ruhr: Seedbed of the World War II, La Haya, Martinus Nijhoff, 1968.

6 Gillingham, John, J., Industry and Politics in the Third Reich: Ruhr Coal, Hitler and Europe, Nueva York, Columbia University Press, 1985. 
ción" de esa región estratégica. ${ }^{7}$ Mientras que la posibilidad de que los rusos pudieran influir en el Ruhr se alejaba, la asignación a Francia de una "zona de ocupación" y de un lugar en el Consejo de Control para Alemania favorecerían su propuesta de una administración aliada del carbón y acero alemanes.

Desde los tiempos de la guerra, el general De Gaulle había promovido la idea de retirarle a Alemania la posesión del Ruhr y otorgarle su control a una instancia internacional en donde participaran los países dependientes del carbón de esa región. ${ }^{8}$ Luego de haber sufrido en carne propia la experiencia de una guerra con Alemania y de dos guerras "mundiales", los franceses se habían finalmente convencido de que la única forma de protegerse de la amenaza militar era reducir, de raíz, la capacidad alemana de acción independiente. ${ }^{9}$ El gran reto era concebir un mecanismo que hiciera "materialmente imposible" una nueva guerra. Un primer paso en esa dirección lo constituye el Acuerdo del Ruhr suscrito por Estados Unidos, el Reino Unido, Francia y los países del Benelux (Bélgica, Holanda y Luxemburgo) el 28 de abril de 1949. ${ }^{10}$

Este acuerdo creó la Autoridad Internacional del Ruhr, integrada por los seis países indicados más Alemania Occidental. Su objetivo era garantizar que "los recursos del Ruhr no serán utilizados en el futuro para el propósito de la agresión”. Sin embargo, a pesar de sus amplias facultades formales, dicho órgano se limitó a "determinar la cantidad de carbón que sería exportado por Alemania Occidental", sobre bases comerciales y no de reparación de los daños de guerra causados. ${ }^{11}$ Hasta aquí, todo hacia suponer que se iba a repetir lo acontecido después de la Primera Guerra. Pero no, para entonces los franceses habían ya concebido una novedosa estrategia de integración para Europa: el llamado Plan Schu-

7 Greenwood, Sean, "Bevin, the Ruhr and the Division of Germany: August 1945-December 1946”, The Historical Journal, vol. 29, núm. 1, 1986, pp. 204 y 205.

8 Layton Funk, Arthur, Charles de Gaulle: The Crucial Years 1943-1944, Norman, University of Oklahoma Press, 1959.

9 Paton, H. J., "Truncation as a Means of Preventing German Aggression”, International Affairs, vol. 21, núm. 2, 1945, pp. 182-186; Sethur, Frederick, op. cit., nota 3, pp. 503-509.

10 Una versión íntegra de este Acuerdo puede encontrarse en: "Agreement for establishment of an international authority for the Ruhr", The American Journal of International Law, vol. 43, núm. 3, 1949, pp. 140-153.

11 Yoder, Amos, "The Ruhr Authority and the German Problem", The Review of Politics, vol. 17, núm. 3, 1955, p. 354. 
man. Este importante plan provocaría el nacimiento de la Comunidad Europea del Carbón y del Acero y la disolución de la Autoridad del Ruhr en febrero de $1953 .^{12}$

A pesar de su nombre, la autoría del Plan Schuman debe ser atribuida a Jean Monnet y a sus colaboradores más cercanos. Si bien la vida y obra de Monnet han sido profusamente estudiadas, ${ }^{13}$ resulta importante aquí recordar su paso por el Commissariat Générale au Plan —el nuevo órgano francés de planeación - a principios de 1946, así como el innovador plan económico que él y su equipo ahí elaboraron. A diferencia de sus predecesores, este plan condicionó su éxito a la creación de "un marco para la economía europea en el cual la reconstrucción y modernización de la económica francesa pudiera ser logrado". ${ }^{14}$ Dicho en términos más específicos, para que Francia pudiera reconstruirse y prosperar necesitaba de los recursos del Ruhr. Al ubicar el futuro de Francia más allá de sus fronteras nacionales, el Plan de Monnet contribuyó a fortalecer la demanda francesa por un control internacional de esa región.

Entre los seis sectores que incluyó el Plan de Monnet destacaban el carbón, la electricidad, el cemento y el acero, insumos esenciales para una estrategia de desarrollo industrial como la propuesta para Francia. Desde la aprobación misma del plan en marzo de 1946, este país dejó en claro que el éxito de su estrategia dependía de que los aliados le permitieran un mayor acceso al carbón del Ruhr y retardaran la reindustrialización alemana. Sin embargo, frente al temor de una expansión soviética en territorio europeo, los estadounidenses decidieron en 1948 no sólo ampliar su apoyo financiero a la región, sino impulsar la formación de Alemania Occidental. Si bien los abundantes recursos del Plan Marshall salvaron al Plan de Monnet de la bancarrota, la nueva actitud de los esta-

12 Las causas de estos eventos fueron plenamente justificadas por el propio secretario ejecutivo de Autoridad del Ruhr, para quien la futura Comunidad sería una "organización internacional más apropiada" que esa Autoridad. Kaeckenbeeck, H. E. Georges, "The International Authority for the Ruhr and the Schuman Plan", Transactions of the Grotius Society, vol. 37, 1951, p. 7.

13 Véanse, por ejemplo, la obra de Duchêne, François, Jean Monnet. The First Statesman of Interdependence, Nueva York-Londres, Norton, 1994 y la de Brinkley, Douglas y Hackett, Clifford (eds.), The Jean Monnet: The Path to European Unity, Londres, Macmillan, 1991.

14 Lynch, Frances M. B., "Resolving the Paradox of the Monnet Plan: National and International Planning in French Reconstruction", The Economic History Review, nueva serie, vol. 37, núm. 2, 1984, p. 242. 
dounidenses hacia la "cuestión alemana" obligó a los franceses a reformular su política exterior hacia su "ancestral enemigo". ${ }^{15}$

Para principios de 1949, Jean Monnet tenía ya claras las ideas centrales que darían cuerpo a la Declaración Schuman. ${ }^{16}$ A diferencia de su plan nacional, los esfuerzos se centrarían sólo en el carbón y en el acero. No es casual que eligiera esos dos recursos, si se considera su importancia estratégica tanto para la reconstrucción como para la guerra. Además, pensaba que entre más países europeos regularan la producción de esos recursos más difícil sería el re-armamentismo unilateral por parte de Alemania Occidental. En esta lógica, el Reino Unido debía estar en la lista de aliados clave. Así, aprovechando su alto cargo y prestigio personal, no sólo insistió en una unión económica entre ambos países, sino que inicio negociaciones en esa dirección con su contraparte sir Edwin Plowden. Sin embargo, las pláticas terminaron a finales de aquel año sin que Monnet pudiera conseguir el apoyo británico. ${ }^{17}$

En el centro de este fracaso estaban las posturas antagónicas de ambos gobiernos sobre cual debía ser el futuro de Europa. Mientras que el británico buscaba construir una "Comunidad transatlántica" con los Estados Unidos sobre bases convencionales, el francés intentaba construir una inédita e innovadora "federación europea". ${ }^{18}$ En esencia, el concepto de "supranacionalidad" manejado por Monnet y Schuman imposibilitaba cualquier posibilidad de alianza. ${ }^{19} \mathrm{El}$ inicio de la Guerra de Corea a principios de 1950 llevaría a los Estados Unidos a favorecer la segunda postura, misma que había sido ya sugerida por ministro del exterior francés Schuman en un viaje de trabajo realizado a este país en septiembre de 1949. A solicitud del gobierno francés, y en escasas tres páginas, Monnet presentó un borrador de su Plan a los ministros Bidault y Schuman a finales de $1950 .{ }^{20}$

15 Lovett, A. W., "The United States and the Schuman Plan. A Study in French Diplomacy 1950-1952”, The Historical Journal, vol. 39, núm. 2, 1996, pp. 428 y 429.

16 Monnet, Jean, Memoirs, Londres, Collins, 1978, pp. 261 y ss.

17 Bullen, Roger y Pelly, M. E. (eds.), Documents on British Policy Overseas, vol. 1: The Schuman Plan, the Council of Europe and Western European Integration, 1950-1952, Londres, HMSO, 1986, serie II, pp. 127-129.

18 Sahm, Ulrich, "Britain and Europe, 1950", comentario de Kenneth Younger, International Affairs, vol. 43, núm. 1, 1967, pp. 12 y 13.

19 Kaeckenbeeck, H. E. Georges, op. cit., nota 12, p. 11.

20 Lovett, A. W., op. cit., nota 15, pp. 430 y 431. 
El 9 de mayo de 1950, Schuman hizo su famosa Declaración, la cual a partir de entonces sería llamada Plan Schuman. En su parte medular, el ministro señaló: "El Gobierno francés propone que se someta el conjunto de la producción franco-alemana de carbón y de acero a una alta autoridad común, en una organización abierta a los demás países de Europa”. Con ello se busca, agregó, introducir "el fermento de una comunidad más profunda entre países que durante tanto tiempo se han enfrentado en divisiones sangrientas". Asimismo, convocó a la firma de un tratado internacional que adopte los "principios y compromisos esenciales anteriormente expuestos". Finalmente, Schuman indicó que en las negociaciones encaminadas a "precisar las normas de aplicación" habría "un árbitro designado de común acuerdo, cuya misión consistiría en velar cuáles acuerdos se ajusten a los principios". ${ }^{21}$

La secuencia de los eventos que siguió es muy conocida, por lo que baste sólo con subrayar su inusual velocidad. El 20 de junio de 1950, se llevó a cabo en París una Conferencia, presidida por Monnet, y a la cual asistieron representantes de Francia, Alemania Occidental, los países del Benelux e Italia. Sin sorpresa, el gobierno inglés no acudió a pesar de haber sido invitado. Ahí, el Grupo de los Seis acordó celebrar el Tratado Constitutivo de la Comunidad Europea del Carbón y del Acero, cuya versión final fue firmada el último día de la Conferencia de Ministros del Exterior que tuvo lugar, también en París, del 12 al 18 de abril de 1951. El Tratado de París - como llamaremos aquí a aquél tratado- fue ratificado por las partes el 25 de junio de 1952 y entró en vigor un mes después.

El 10 de agosto de 1952, la Comunidad Europea del Carbón y del Acero comenzó sus operaciones. En poco más de dos años el Plan Schuman había dejado de ser sólo teoría para convertirse en una realidad. A partir de entonces, el futuro de la naciente comunidad quedó en manos de las instituciones propuestas para llevar a cabo la primera etapa de la construcción de una Europa libre de la amenaza bélica entre vecinos. Ello justifica mirar con detenimiento la naturaleza y alcances jurídicos, pero sobre todo políticos, de dichas instituciones.

21 Declaración Schuman, 1950 (disponible en http://www.robert-schuman.org). 


\section{DIMENSIÓN POLÍTICO-INSTITUCIONAL DE LA COMUNIDAD EUROPEA DEL CARBÓN Y DEL ACERO}

De la sección anterior se desprende que el objetivo central detrás del Plan Schuman era "político más que económico". ${ }^{22}$ En otras palabras, dicho plan buscó dar una solución económica a un problema esencialmente político: la prevención de una nueva guerra por la vía de la integración económica y política de Europa. La elección de Jean Monnet como primer presidente de la Alta Autoridad de la Comunidad Europea del Carbón y del Acero (CECA) dejó claro que el Grupo de los Seis buscaba algo más que "los beneficios materiales de un comercio más libre". ${ }^{23}$ Monnet mismo se encargó de confirmarlo en marzo de 1953, al afirmar que: "Nuestra Comunidad no es una asociación de productores de carbón y acero; es el principio de Europa". ${ }^{24}$ Habría que agregar que tampoco constituía una organización convencional, gracias a su convicción de que "nada es duradero sin instituciones". ${ }^{25}$

Durante los años cuarenta, la guerra había favorecido al resurgimiento del ideal de una Europa unida. Las numerosas y muy diversas propuestas integracionistas culminaron con la creación del Consejo de Europa en 1949. ${ }^{26}$ La gran diferencia entre este Consejo y la CECA radicaba en la forma y el método para alcanzar la tan anhelada unidad. Dicho de otro modo, los distanciaba la manera de abordar un asunto tabú: el papel de la soberanía nacional en el proceso. Mientras que el Consejo fue concebido como un instrumento para la acción de los países participantes, dejando su soberanía intacta, la operación de la Comunidad exigía que los países miembros aceptaran ceder una parte de su soberanía. De ahí que Kriesberg definiera a esta Comunidad como "una institución supra-

22 Driscoll, J., "Early Days in Schumania", The Journal of Industrial Economics, vol. 2, núm. 2, 1954, p. 89.

23 Willis, F. Roy, "Origins and Evolution of the European Communities", Annals of the American Academy of Political and Social Science, vol. 440, 1978, p. 5.

24 Monnet, Jean, Les Etats-Unis d'Europa ont commencée: Discours et allocutions, 1952-1954, París, Laffont, 1955, p. 65.

25 Citado por Dinan, Desmond, Ever Closer Union? An Introduction to the European Community, Boulder, Lynne Renner Publishers, 1994, p. 14.

26 Sobre este tema puede consultarse a Roberson, A. H., "The Council of Europe, 1949-1953-II", The International and Comparative Law Quarterly, vol. 3, núm. 3, 1954, pp. 404-420 y "The Council of Europe, 1949-1953-I", The International and Comparative Law Quarterly, vol. 3, núm. 2, abril de 1954, pp. 235-255. 
nacional con derechos soberanos sobre las industrias del carbón y del acero de las naciones miembros". 27

Sin duda, la gran innovación del Tratado de París fue haber creado una Comunidad con rasgos supranacionales. ${ }^{28}$ El contenido general de ese acuerdo confirma esta intencionalidad. Para disipar cualquier duda, el Tratado hace dos referencias al "carácter supranacional" de las funciones de su órgano ejecutivo (artículo 9o.). ${ }^{29}$ Una de ellas se refiere a la obligación de los países signatarios de no interferir en su funcionamiento. Además de otorgarle personalidad jurídica y puntualizar que gozaría "en cada uno de los Estados miembros de la más amplia capacidad jurídica reconocida a las personas jurídicas nacionales" (artículo 6o.), el Tratado le brindó a la CECA las "inmunidades y privilegios necesarios para el cumplimiento de su misión" dentro del mismo ámbito nacional (artículo 76). Más importante aún, el Grupo de los Seis reconoció obligatoriedad a las decisiones ejecutivas de la Comunidad (artículo 14) y aceptó que sus resoluciones judiciales tuvieran "fuerza ejecutiva en el territorio de los Estados miembros" (artículo 44).

Lo anterior demanda precisar un poco más la división del trabajo al interior de la CECA. Según el Tratado de París, la nueva Comunidad estaría integrada por cuatro órganos primarios: una Alta Autoridad; una Asamblea Común, un Tribunal de Justicia y un Consejo Especial de Ministros (artículo 7o.). Pero, ¿por qué se eligió este particular arreglo institucional? En uno de los muy pocos trabajos sobre el tema, Rittberger afirma que las variaciones en las preferencias de los actores en materia de cooperación son acompañadas por lógicas distintas en el campo de la construcción institucional. De este modo, mientras que para Francia y Alemania la mayor preocupación era su seguridad nacional, para los países del Benelux la cooperación debía servir a propósitos económicos.

27 Kriesberg, Louis, "German Public Opinion and the European Coal and Steel Community”, The Public Opinion Quarterly, vol. 23, núm. 1, 1959, p. 28.

28 Uno de los mejores análisis jurídicos de este tratado continúa siendo el producido por Bebr, Gerhard, "The European Coal and Steel Community: A Political and Legal Innovation", The Yale Law Journal, vol. 63, núm. 1, 1953, pp. 1-43.

29 Tratado Constitutivo de la Comunidad Europea del Carbón y del Acero, 1951 (disponible en http://europa.eu./index_es.htm, rubro). Por economía de espacio, la citación de artículos se hará en el texto principal entre paréntesis. 
Para dicho autor, en suma, la conciliación de ambas posturas responde a la pregunta antes planteada. ${ }^{30}$

Como Monnet observó, no existía "ningún precedente" que pudiera servir como modelo en el diseño del órgano ejecutivo de la Comunidad. ${ }^{31}$ Aunque esgrimiendo diferentes razones, Francia y Alemania llegarían a un punto de acuerdo: la necesidad de una entidad supranacional fuerte. Ello le garantizaba a Francia su seguridad nacional frente a Alemania, y al mismo tiempo le brindaba a Alemania la oportunidad de recobrar algo de la soberanía perdida. El temor de que se pudiera crear una "dictadura de expertos" llevó a los países del Benelux a exigir la inclusión de instituciones que sometieran al órgano ejecutivo a "una rendición de cuentas democrática". La aceptación unánime de que lo anterior sólo podía lograrse a través de instituciones representativas, determinó el arreglo institucional, la distribución de poder y el sistema de pesos y contrapesos de la Comunidad. ${ }^{32}$

La Alta Autoridad fue originalmente concebida como el órgano ejecutivo y administrativo de la Comunidad y, por tanto, quedó encargada de "asegurar la consecución de los objetivos" del Tratado (artículo 8o.). El "carácter supranacional de sus funciones" explica las medidas adoptadas para protegerla de influencias provenientes de los gobiernos nacionales. Sus nueve integrantes — nombrados por seis años, atendiendo sólo a "su competencia general" - debían conducirse con "absoluta independencia", lo que los obligaba a no solicitar ni aceptar "instrucciones de ningún Gobierno". Asimismo, se prohibió que entre ellos hubiera más de dos con la misma nacionalidad. Esta disposición fue complementada con la introducción del sistema de mayoría para la toma de decisiones (artículo 9o.). Finalmente, se estableció que la actividad de la Alta Autoridad sería apoyada por un Comité Consultivo integrado por "productores, trabajadores, usuarios y comerciantes" vinculados con las dos industrias bajo su esfera de influencia.

Al interior de la Comunidad, la actuación de la Alta Autoridad quedó sujeta a tres diferentes controles: uno político, uno jurídico y uno econó-

30 Rittberger, Berthold, "Which Institutions for Post-War Europe? Explaining the Institutional Design of Europe's First Community", Journal of European Public Policy, vol. 8, núm. 5, 2001, pp. 700 y 701.

31 Monnet, Jean, op. cit., nota 16, p. 294.

32 Rittberger, Berthold, op. cit., nota 30, pp. 694-700. 
mico. En primer lugar, ese órgano debía presentar un informe anual de actividades a la Asamblea Común para su discusión en "sesión pública" (artículo 17). Su rechazo por "dos tercios de los votos" traería como consecuencia la renuncia colectiva de los miembros de la Alta Autoridad (artículo 24). Pero, ¿quiénes eran los titulares de esta facultad para emitir este voto de censura?: 78 "representantes de los pueblos" designados por los parlamentos nacionales, de entre sus miembros, o electos "por sufragio universal directo" (artículo 21, 1). ${ }^{33}$ Cabe mencionar que, a diferencia de lo que ocurrió con la Alta Autoridad, la Asamblea Común fue inspirada por la Asamblea Consultiva del Consejo de Europa, creada en mayo de $1949 .{ }^{34}$

En segundo lugar, el Tribunal de Justicia — integrado por siete jueces nombrados de "común acuerdo" por los gobiernos de "entre personalidades que ofrezcan absolutas garantías de independencia y competencia" (artículo 32) - fue facultado para controlar la legalidad de los actos y omisiones de la Alta autoridad. Asimismo, los miembros de ésta última podían "ser cesados por el Tribunal, a instancia de la Alta Autoridad o del Consejo [Especial de Ministros]", en los casos previstos por el Tratado (artículo 12). Por otro lado, el Tribunal disponía de la facultad para anular, a petición de uno de los Estados miembros o de la Alta Autoridad, los acuerdos de la Asamblea o del Consejo" (artículo 38). En general, ese órgano auténticamente jurisdiccional tenía en sus manos garantizar "el respeto del derecho en la interpretación y aplicación" del Tratado, así como de sus "reglamentos de ejecución" (artículo 31).

En tercer lugar, el control económico de la Alta Autoridad era ejercido por el Consejo Especial de Ministros, único órgano realmente intergubernamental. ${ }^{35} \mathrm{Su}$ función principal era la "de armonizar la acción de la

33 A Alemania, Francia e Italia le correspondieron 18 representantes por país; a Bélgica y Holanda, 10 por país, y a Luxemburgo 4 (artículo 21, 2).

34 El Consejo de Europa estaba integrado por dos órganos: el Comité de Ministros del Exterior y una Asamblea Consultiva. El primero de ellos se ajustaba a los patrones convencionales de cooperación intergubernamental, mientras que el segundo constituyó un novedoso ensayo institucional, ya que sus miembros provenían de los parlamentos nacionales de los países participantes en ese Consejo. Roberson, A. H., "The Council of Europe, 1949-1953-I", op. cit, nota 26, p. 235.

35 Este Consejo fue considerado análogo a una "Cámara alta de Estados" por Lever, Jeremy, "International Legal Aspects of the European Coal and Steel Community", Transactions of the Grotius Society, vol. 44, 1958, p. 206. 
Alta Autoridad con la de los Gobiernos" de los seis países signatarios (artículo 26). Este Consejo estaba integrado por un representante de cada uno de ellos y su presidencia sería ejercida "por rotación” trimestral, "siguiendo el orden alfabético de los Estados miembros" (artículo 27). Dicho órgano podía pedir a la Alta Autoridad se abocara "al estudio de todas las propuestas y medidas que él considere oportunas y necesarias para la consecución de los objetivos comunes" (artículo 26). Asimismo, le correspondió nombrar, de manera indirecta, a los miembros del Consejo Consultivo. En general, la función de este Consejo no era supervisar a la Alta Autoridad, sino sólo asistirla con su voto en la toma de las decisiones.

Un politólogo del momento calificó "el establecimiento de órganos supranacionales por un tratado internacional, como un nuevo experimento en organización internacional", mismo que "sería realizado por primera vez en el nivel regional de la Europa no comunista". ${ }^{36}$ Por su lado, un jurista observó que el arreglo institucional de la nueva Comunidad implicaba "una fusión (merger) de soberanías y no sólo coordinación o cooperación". ${ }^{37}$ No obstante, estaba todavía por verse si esta teoría institucional podría ser llevada a la práctica exitosamente.

\section{PRIMERAS ACCIONES Y LOGROS DE LA COMUNIDAD, 1952-1957}

La puesta en operación de la Comunidad no resultó tarea fácil. ${ }^{38}$ Por una parte estaba la resistencia de amplios sectores de los gobiernos nacionales que no veían con agrado la inevitable cesión de soberanía a las instancias comunitarias y, por el otro, la natural desconfianza de las grandes monopolios económicos privados y públicos al sentir amenazados sus intereses. ${ }^{39}$ Por ejemplo, influyentes asociaciones comerciales francesas se habían opuesto al intento de "destruir el principio esencial de la re-

36 Kunz, Josef L., "Supra-National Organs", The American Journal of International Law, vol. 46, núm. 4, 1952, p. 690 (las cursivas son agregadas).

37 Van Raalte, Ernest, "The Treaty Constituting the European Coal and Steel Community", The International and Comparative Law Quarterly, vol. 1, núm. 1, 1952, p. 74.

38 Sobre los problemas enfrentados, véase a Diebold, William Jr., The Schuman Plan: A Study in economic cooperation, Nueva York, Oxford University Press, 1959.

39 Parker, William N., "The Schuman Plan-A preliminary prediction", International Organization, vol. 6, núm. 3, 1952, pp. 384-387. 
presentación empresarial". ${ }^{40}$ Entre los alemanes, el nivel de aceptación del Plan Schuman había caído del $75 \%$ en junio de 1950 al $47 \%$ en enero de $1952 .{ }^{41}$ En contra también trabajó el poco interés que el nacimiento y proyecto de la CECA despertó en los influyentes círculos académicos anglosajones. ${ }^{42}$

A pesar de todo, la Comunidad comenzó operaciones en Luxemburgo el 10 de agosto de 1952 y una actividad febril caracteriza sus dos primeros años de vida. ${ }^{43}$ Poco antes, los miembros de la Alta Autoridad habían sido nombrados, quedando Monnet como su presidente. La primera gran decisión de este órgano fue establecer — en diciembre de 1952 - un derecho sobre la producción de carbón y de acero. El carácter obligatorio de la medida lo convierte en el "primer impuesto europeo. ${ }^{44}$ Para principios de 1953, sus cuatro órganos habían sido integrados y estaban funcionando. Ello permitió que la Alta Autoridad pudiera declarar abierto el mercado común del carbón en los territorios de los seis Estados miembros el 10 de febrero de 1953 y el correspondiente al acero el 1o. de mayo siguiente.

Destaca que el sistema de pesos y contrapesos entre las instituciones de la Comunidad previsto por el Tratado haya operado casi de inmediato. Entre 1953 y 1954, la Alta Autoridad presentó cinco informes de labores a la Asamblea Común. Para finales de 1954, esta Asamblea se había reunido ocho veces, normalmente, con la asistencia de miembros de la Alta Autoridad. Por su lado, para finales de ese mismo año, el Consejo de Mi-

40 Ehrmann, Henry W., "The French Trade Associations and the Ratification of the Schuman Plan", World Politics, vol. 6, núm. 4, 1964, p. 453.

41 Kriesberg, Louis, "German Public Opinion and the European Coal and Steel Community”, op. cit., nota 27, p. 29. Según este autor, dicha tendencia se revertiría después del inicio de operaciones de la Comunidad.

42 El mejor indicador es el bajo número de artículos y libros especializados publicados en el periodo 1951-1957. En ese lapso, por ejemplo, el Yale Law Journal sólo publicó un artículo y la reseña de un libro (vols. 62 a 67); The International and Comparative Law Quarterly publicó un artículo y dos notas (vols. 1 a 6). El primer libro en inglés sobre el tema fue Mason, Henry L., The European Coal and Steel Community: Experiment in Supranationalism, La Haya, Martinus Nijhoff, 1955.

43 Una descripción de las primeras actividades de la Comunidad puede encontrarse en "European Coal and Steel Community", International Organization, vol. 7, núm. 2, 1953, pp. 293-295 y en "European Coal and Steel Community", International Organization, vol. 8, núm. 2, 1954, pp. 286-290.

44 Mendershausen, Horst, "First tests of the Schuman Plan", The Review of Economics and Statistics, vol. 35, núm. 4, 1953, p. 272. 
nistros había celebrado veinte sesiones en donde, por lo regular, se discutieron las actividad de la Alta Autoridad. En el mismo periodo, el Tribunal de Justicia había iniciado diez procesos, en la mayoría de los cuales se cuestionaron decisiones de la Alta Autoridad, y ésta rectificaría, en su momento, algunas de ellas en acatamiento de sus sentencias. ${ }^{45}$

Los trabajos de la Alta Autoridad se centraron en cuatro rubros: mercado común, inversión y finanzas, condiciones laborales y relaciones exteriores. Por lo que hace al primero de ellos, la magnitud de la tarea a realizar es ilustrada por la situación prevaleciente en la región. Enormes cárteles, tanto nacionales como internacionales, controlaban la producción del acero. Por ejemplo, el Internacional Steel Cartel, apoyado por los acereros de siete países europeos, llegó a controlar un tercio de la producción mundial y dos tercios de las exportaciones mundiales. En la extracción de carbón los "monopolios eran la regla, aunque sólo a una escala nacional". Por tanto, el mayor reto de la Comunidad era, entonces, establecer una competencia real entre empresas en un contexto donde era "prácticamente desconocida". ${ }^{46}$

Desde el fin de la guerra, la demanda de carbón en la futura "comunidad Schuman" había excedido la oferta. ${ }^{47}$ La principal causa era una sensible disminución en la producción de ese recurso. En 1949, por ejemplo, dicha región produjo el 15.8\% del carbón mundial en contraste con el 20\% alcanzado en 1939. La acción de la CECA transformó radicalmente este panorama. Durante 1954, el volumen del comercio de carbón entre el Grupo de los Seis fue 25\% superior al de 1952, y algo similar ocurrió con el acero. En especial, "las órdenes alemanas de acero francés de ese año mostraron un incremento del 65\%, comparado con las cifras de 1952". ${ }^{48}$ Esta tendencia, misma que se mantendría en los años siguientes, era un indicador de que la Comunidad había logrado sentar las bases de "la primera ley antitrust europea". ${ }^{49}$

45 Merry, Henry J., "The European Coal and Steel Community: Operations of the High Authority", The Western Political Quarterly, vol. 8, núm. 2, 1955, pp. 179-181.

46 Schmitt, Hans A., "The European Coal and Steel Community: Operations of the First Antitrust Law, 1952-1958”, The Business History Review, vol. 38, núm. 1, 1964, p. 103.

47 Zawadzki, K. K. F., "The Economics of the Schuman Plan", Oxford Economic Papers, nueva serie, vol. 5, núm. 2, 1953, pp. 157 y 158.

48 Merry, Henry J., op. cit., nota 45, p. 182.

49 Schmitt, Hans A., op. cit., nota 46, p. 103. 
Para principios de 1958, las restricciones arancelarias y aduaneras al comercio del carbón y del acero entre los Estados miembros, así como las prácticas discriminatorias, habían sido disminuidas sustancialmente. Este logro no puede ser explicado sin considerar la independencia y autoridad real de la maquinaria institucional de la Comunidad vis-à-vis los gobiernos nacionales, y los agentes económicos y sociales involucrados. En particular, la actuación de la Alta Autoridad fue no sólo supervisada, sino también legitimada por el Tribunal de Justicia, actuando como "guardián" del Estado de derecho de la Comunidad. Durante 1954, dicho Tribunal emitió sus primeras cuatro sentencias, en las cuales reiteró la obligación de los productores de carbón y acero de publicar sus precios de venta. Para 1957, su actividad se había extendido a la revisión de las decisiones de la Alta Autoridad en prácticamente todos los campos de su actividad..$^{50}$

Durante los dos primeros años, la labor de planeación de la Alta Autoridad en materia de inversión y condiciones laborales fue intensa y ambiciosa. A principios de 1954, un plan de cinco puntos fue anunciado para incrementar la producción de acero de 42 a 50 millones de toneladas por año, esto es, cerca de la mitad de la producción estadounidense. Además de inversión en infraestructura y en modernización de la industria minera, dicho plan contemplaba la construcción de casas para los mineros. Además de revisar las condiciones salariares de los trabajadores en sus dos sectores de competencia, la Alta Autoridad elaboró un plan para permitir su libre movilidad dentro del territorio de la Comunidad. ${ }^{51}$ Con estas medidas se buscaba dar cumplimiento al objetivo de "promover la mejora de las condiciones de vida y de trabajo de los trabajadores" establecido por artículo 3o., inciso e, del Tratado.

No menos importante fue la labor de la Alta Autoridad hacia el exterior. Las frecuentes visitas de Monnet a los Estados Unidos lograron el apoyo político y financiero de este país, lo que sin duda contribuyó a la independencia y prestigio internacional de la emergente Comunidad. ${ }^{52}$ En 1954, por ejemplo, ese país autorizó un préstamo de 100 millones

50 Stein, Eric, "The Court of Justice of the European Coal and Steel Community: 1954-1957”, The American Journal of International Law, vol. 51, núm. 4, 1957, p. 829.

51 Merry, Henry J., op. cit., nota 45, pp. 174 y 175.

52 Spierenburg, Dirk y Poiderin, Raymond, The History of the High Authority of the European Coal and Steel Community: Supranationality in Operation, Londres, Weidenfeld \& Nicolson, 1994, pp. 98-112. 
de dólares para financiar los programas de inversión de esta última. En general, las relaciones de la Comunidad con otras organizaciones internacionales y terceros países fueron muy activas desde el inicio. Destaca su participación en el Acuerdo General sobre Aranceles y Comercio (GATT, por sus siglas en inglés). La percepción del éxito de la Comunidad provocó que otros países establecieran delegaciones en Luxemburgo para observar sus trabajos. A Gran Bretaña y los Estados Unidos, siguieron Suecia, Noruega, Suiza, Dinamarca, Austria y Japón, con los cuales la Comunidad estableció crecientes relaciones comerciales y económicas.

En especial, resulta importante resaltar la apertura de negociaciones entre la Comunidad y la Gran Bretaña para definir sus relaciones a principios de 1954. Ello como resultado de la nueva propuesta de Monnet de crear "una asociación entre los dos mercados". Esta vez, sí se logró alcanzar un acuerdo a finales de ese mismo año. No obstante, dicho acuerdo no fue firmado por la Comunidad como tal, sino por los países del Grupo de los Seis. De cualquier forma, gracias a él fue establecido un Consejo de Asociación - compuesto por cuatro representantes de la Alta Autoridad y cuatro de la Gran Bretaña-encargado de intercambiar información "en materia de intereses comunes vinculados con el carbón y el acero". Asimismo, se acordó que cuando el Consejo de Ministros de la Comunidad manejara asuntos del interés de este último país, uno de sus representantes participaría en las reuniones del Consejo. ${ }^{53}$

Para principios de 1958, los logros económicos de la Comunidad habían sido considerados como "impresionantes". ${ }^{4}$ No era para menos, el complejo carbonífero y acerero de Ruhr-Lorraine-Saar se había convertido en "uno de los más poderosos centros de producción de mundo", al contribuir con casi las dos terceras partes del acero que ingresaba al mer-

53 "European Coal and Steel Community", International Organization, vol. 9, núm. 2, 1955, pp. 314 y 315.

54 Sanderson, Fred H., "The Five-Year Experience of the European Coal and Steel Community", International Organization, vol. 12, núm. 2, 1958, p. 193. Esta primera valoración sería más tarde sustentada cuantitativamente por un grupo de expertos independientes dirigidos por el doctor Rolf Wagenführ. Wagenführ, Rolf, La Communauté Européenne du Charbon et de l'Acier, 1952-62: Les dix premières années d'une intégration partielle, Alta Autoridad de la Comunidad del Carbón y del Acero, Luxemburgo, 1963. 
cado mundial. ${ }^{55}$ Sin embargo, este logro, pero sobre todo los múltiples obstáculos y dificultades enfrentados para alcanzarlo, pusieron de manifiesto la necesidad de avanzar hacia una "unión económica" más completa. ${ }^{56}$ En este renglón, las instituciones de la Comunidad también habían trabajado arduamente, como veremos a continuación.

\section{DE LA COMUNIDAD EUROPA DEL CARBÓN Y DEL ACERO A LA UNIÓN EUROPEA}

La actual Unión Europea (UE) es más resultado de un plan que de factores contingentes, más producto de la obstinación por conservar un rumbo que del azar. Una comparación entre la estrategia inicial de integración y lo ocurrido en más de medio siglo en esa región, sustenta plenamente esta afirmación. Sin embargo, el torrente de acontecimientos que ha tenido lugar en ese periodo ha tenido el efecto de obscurecer la gran congruencia observada entre los objetivos y estrategias del Plan Schuman - precisados y formalizados por el Tratado de París-, y la dirección que ha seguido el proceso europeo de integración. El que dicho Plan se haya cumplido casi al pie de la letra, y además con éxito, es, sin duda, un hecho excepcional en el campo de la implementación de planes y programas. ${ }^{57}$

Para comenzar diremos que esta inusual relación entre teoría y práctica no podría entenderse plenamente si se ignoran los acontecimientos que conectan al Tratado de París con los Tratados de Roma de 1958. A pesar de ello, el primero sigue siendo el Tratado fundacional menos estudiado. En 1950, Schuman había señalado que "Europa no se hará de una vez ni en una obra de conjunto: se hará gracias a realizaciones concretas", y agregó que su propuesta constituía "la primera etapa de la federación europea". ${ }^{58}$ Por su parte, en el Tratado de París se puede leer que los

55 Rosen, Martin J., "The Brussels Entente: Export combination in the world steel market”, University of Pennsylvania Law Review, vol. 106, núm. 8, 1958, p. 1079.

56 Lister, Louis, Europe's Coal and Steel Community: An Experiment in Economic Union, Nueva York, Twentieth Century Fund, 1960, pp. 25 y 29.

57 Consúltese la obra de Pressman, Jeffrey L. y Wildavsky, Aaron, A., Implementación: Cómo grandes expectativas concebidas en Washington se frustran en Oakland, México, CNCP-AP-FCE, 1998.

58 Declaración Schuman, op. cit., nota 21. 
países signatarios estaban "resueltos" a construir "los primeros cimientos de una comunidad más amplia y profunda entre pueblos". ${ }^{59}$

No había duda, entonces, que la supranacionalización del carbón y del acero había sido pensada como el inicio de una integración económica y política gradual. Un prematuro intento por acelerar el proceso pondría en grave riesgo su continuidad. El 27 de mayo de 1952, esto es, algunos meses antes de que la CECA iniciara operaciones, el Grupo de los Seis - al margen de esa Comunidad - firmó un Tratado por el cual se creaba una Comunidad Europea de Defensa (Plan Pleven). ${ }^{60}$ En septiembre de 1952, los seis miembros del Consejo de Ministros de la CECA -haciendo eco de las inquietudes y proyectos integracionistas planteados en el Consejo de Europa - invitaron a los futuros miembros de la Asamblea Común a que elaboraran el borrador de un Tratado para la constitución de una Comunidad Política Europea. ${ }^{61}$

Aunque la invitación fue aceptada por esa Asamblea en su sesión inaugural, todo el proyecto fracasó cuando la Asamblea Nacional francesa se opuso a la creación de la primera de las Comunidades mencionadas en 1954. Este hecho provocó la renuncia de Monnet a la presidencia de la Alta Autoridad, pero también sirvió para que los países del Benelux propusieran que la integración europea se ampliara a nuevos sectores de la economía (Memorando Benelux) y para que la Asamblea Común elaborara un plan para "fortalecer las instituciones de la Comunidad". El apoyo que recibieron ambas propuestas por los ministros del exterior del Grupo de los Seis se reflejó en la elección del belga Paul-Henri Spaak como nuevo presidente de la Alta Autoridad en junio de 1955. ${ }^{62}$

En su discurso de despedida, Monnet expresó que el "impulso" para "transferir nuevos poderes a las instituciones europeas" sólo podía venir "desde fuera" de la Comunidad. ${ }^{63}$ Esta idea fue materializada a través de

59 Tratado Constitutivo de la Comunidad Europea del Carbón y del Acero, op. cit., nota 29, Prefacio (la palabra "resueltos" esta en mayúsculas en el original).

60 Briggs, Herbert W., "The proposed European Political Community", The American Journal of International Law, vol. 48, núm. 1, 1954, p. 110.

61 Karp, Basil, "The draft constitution for a European Political Community", International Organization, vol. 8, núm. 2, 1954, pp. 183 y 187.

62 Yondorf, Walter, "Monnet and the Action Committee: The formative period of the European Communities", International Organization, vol. 19, núm. 4, 1965, pp. 895 y 896.

63 Monnet, Jean, op. cit., nota 24, p. 102. 
la creación del Comité de Acción para los Estados Unidos de Europa en octubre de 1955. Desde este foro, Monnet y un grupo de líderes políticos europeos, pequeño pero muy influyente, se dieron a la tarea de respaldar a Spaak, a través de generar apoyo de partidos políticos, parlamentos, gobiernos y opinión pública, tanto dentro como fuera de las fronteras del Grupo de los Seis, durante las negociaciones de los Tratados de Roma. Luego de su firma, dicho Comité jugaría un papel decisivo en su ratificación. ${ }^{64}$

La creación de la Comunidad Europea de Energía Atómica y de la Comunidad Económica Europea (CEE) dio la razón a los autores del Plan Schuman. Para tener éxito, la integración debía ser gradual y comenzar por lo económico. No es casual de que en el texto de los Tratados de Roma, por ejemplo, se haya evitado utilizar la palabra supranacionalidad. ${ }^{65}$ Este segundo gran "paso" — la formación de tres Comunidadesy los sucesivos, no hacen más que confirmar la sujeción al plan original, así como su exitosa materialización a pesar de los innumerables obstáculos enfrentados. Entre ellos se encuentran las obstrucciones del presidente de Gaulle al proceso europeo de integración durante años los sesenta ${ }^{66}$ $\mathrm{y}$, más tarde, los graves duraderos problemas económicos que provocó el aumento de los precios del petróleo. ${ }^{67}$

A partir de Tratados de Roma, el ámbito de acción económica de la CCE se amplió sistemáticamente. Por ello, el Consejo Europeo decidió en 1988 que era tiempo de construir "una unión monetaria integral a través de una estrategia de cambios graduales". El Reporte Delors estableció tres etapas para alcanzar dicho objetivo, el cual exigía la creación de una nueva institución supranacional: el Banco Central Europeo. El Tratado de Maastricht de 1992, fiel a este programa, sentó las bases jurídicas e institucionales de la actual Unión Monetaria Europea tendentes a la in-

64 Yondorf, Walter, op. cit., nota 62, pp. 897-901.

65 Efron, Reuben y Nanes, Allan S., "The Common Market and Euratom Treaties: Supranationality and the Integration of Europe", The International and Comparative Law Quarterly, vol. 6, núm. 4, 1957, p. 673.

66 Si se desea abundar sobre el tema, véase Serfaty, Simon, France, de Gaulle, and Europe: The Policy of the Fourth and Fifth Republics toward the Continent, Baltimore, Johns Hopkins Press, 1968 y Lynch, Frances M. B., France and the International Economy: From Vichy to the Treaty of Rome, Londres, Routledge, 1997.

67 Lintner, Valerio, "European Monetary Union: Developments, Implications and Prospects", en Richarson, Jeremy (ed.), European Union: Power and Policy-Making, 2a. ed., Londres-Nueva York, Routledge, 2001, pp. 325-329. 
troducción de una moneda común: el euro. ${ }^{68}$ Por todo ello, muy pocos se atreverían a negar que el "mercado común" a que refería el artículo primero del Tratado de París — aunque todavía con muchas imperfecciones- es hoy una realidad.

Más importante aún, la acción de las instituciones comunitarias no se ha limitado exclusivamente al campo económico y social. Gradualmente, su influencia se ha extendido al ámbito político y diplomático. Especialmente a partir del fin de la Guerra Fría, los temas de defensa y seguridad regional ocupan un lugar destacado en la agenda europea. ${ }^{69}$ La creación de la UE en 1993 y la firma del Tratado que establece una Constitución para Europa en 2004 parecen confirmar que la materialización del viejo anhelo de crear una verdadera Comunidad Política Europea como "une entité juridique unique" —frustrado por la Asamblea francesa en 1952está cada vez más cercana. ${ }^{70}$

La misma congruencia entre teoría y práctica se observa aún con mayor claridad por lo que hace al compromiso hecho por Schuman de que la Comunidad sería una "organización abierta a los demás países de Europa". ${ }^{71}$ Así ha sido desde el mismo Tratado de París. En 1973, ingresaron Dinamarca, Irlanda y la Gran Bretaña, esta última más de veinte años después de haber sido invitada por primera vez a participar. Siguió Grecia (1981) y luego España y Portugal (1986). En 1995, se incorporaron Austria, Finlandia y Suecia. Esta política de acceso abierto fue nuevamente reiterada por el Tratado Niza de 2001 y por el ingreso de diez nuevos países en mayo de 2004. La firma del último tratado de adhesión en Luxemburgo el 25 de abril de 2005 —instrumento que permitió el ingreso de Bulgaria y Rumania a la Unión Europea a partir de enero de 2007- obliga a recordar las palabras del ministro francés Georges Bidault, cuando en 1950 señaló que el objetivo último del Plan Schuman era construir "una vasta región, del Mar del Norte al Mediterráneo, que comprenda a todos los países de Europa Occidental con una Alemania democrática y bajo la seguridad protectora de un control internacional, el

68 Torres Espinosa, Eduardo, "El Banco Central Europeo: Aspectos jurídicos, institucionales y políticos", Anuario Mexicano de Derecho Internacional, vol. VII, enero de 2007, pp. 351-377.

69 Smith, Michael, “The EU as an International Actor”, en Richarson, Jeremy (ed.), op. cit., nota 67, pp. 290 y 291.

70 Briggs, Herbert W., op. cit., nota 60, p. 113.

71 Declaración Schuman, op. cit., nota 21. 
cual asegure la libre circulación de bienes, personas y capital, proveyendo una prosperidad real para todos, y al mismo tiempo proporcionando un nuevo elemento de estabilidad para el mundo". ${ }^{72}$

Estos avances hacia una integración económica y política total obligan, nuevamente, a voltear la mirada hacia su motor supranacional: las instituciones comunitarias. En esta materia también se observa la misma congruencia entre teoría y práctica, entre plan y realidad. Tal vez la única desviación fue muy pronto eliminada. Los Tratados de Roma provocaron que cada una de las tres comunidades tuviera "sus propios consejos y comisiones ejecutivas". ${ }^{73}$ Pero, el Tratado de Fusión de 1965 —en vigor a partir de 1967- dio fin a esta dispersión institucional, retomando el espíritu del artículo 1o. del Tratado de París que expresamente hablaba de "instituciones comunes". Desde entonces se regresó al arreglo institucional cuatripartita con el que tan exitosamente había operado la primera Comunidad.

Sí, los nombres y atribuciones de sus cuatro componentes primarios han cambiado, y otras muchas entidades han sido creadas. Sin embargo, la arquitectura institucional de la actual Unión Europea es, en esencia, la misma que los autores del Plan Schuman no sólo concibieron para la CECA, sino que vislumbraron para el futuro. La dirección del cambio y desarrollo institucional que ha tenido lugar desde 1952 parece confirmar que el edificio institucional de la UE está cada vez más cerca de las ideas de sus diseñadores. Un paso importante lo constituye el Tratado de Ámsterdam de 1999, el cual buscó fortalecer y consolidar la base institucional de la UE de acuerdo con esas ideas. Previendo una futura ampliación, el Tratado de Niza de 2001 sólo vino a confirmar esa intención.

Un dato parece claro, en poco más de medio siglo, el crecimiento institucional e importancia de las cuatro instituciones europeas fundamentales se "ha incrementado dramáticamente". ${ }^{74}$ La actual Comisión Europea (antes Alta Autoridad) ha confirmado, una y otra vez, su papel como autoridad ejecutiva supranacional, y sus atribuciones siguen am-

72 Citado por McKesson, John, A., “The Schuman Plan”, Political Science Quarterly, vol. 67, núm. 1, 1952, p. 25.

73 Torres Espinosa, Eduardo, "Integración europea y globalización: Una perspectiva institucional”, Anuario Mexicano de Derecho Internacional, vol. V, enero de 2005, p. 503.

74 Dorussen, Han y Nanou, Kyriaki, "European Integration, Intergovernmental Bargaining, and Convergence of Party Programmes", European Union Politics, vol. 7, núm. 2, 2006, p. 236. 
pliándose. ${ }^{75} \mathrm{Al}$ mismo tiempo, los controles sobre su creciente poder han aumentado con la misma velocidad como resultado del creciente fortalecimiento de dos instituciones: el Parlamento Europeo y el Tribunal de Justicia Europeo. No hay duda que el primero dejó hace mucho de ser una mera asamblea consultiva para convertirse en un órgano con funciones legislativas reales, ${ }^{76}$ mientras que el segundo constituye "una corte internacional inusualmente influyente". ${ }^{77}$ Por su parte, el Consejo de Ministros se ha convertido en algo mucho más complejo que un simple foro intergubernamental. ${ }^{78}$

Hoy, tanto la UE -incluidas sus instituciones y toma de decisiones - como la fase actual del proceso de integración son abordadas desde muy diversos enfoques teóricos. A primera vista parecería que los grandes debates que han provocado sus también muy variadas interpretaciones son inéditos. Sin embargo, existe una vinculación entre dichos debates y las ya olvidadas, pero aún relevantes, interpretaciones y diferencias de opinión que originaron en su momento el Plan Schuman y el Tratado de París, como argumentaremos en la última sección de este trabajo.

\section{LOS DEBATES ACTUALES SOBRE LA UNIÓN EUROPEA A LA LUZ DE SUS PRIMERAS INTERPRETACIONES}

Se ha afirmado que en los últimos quince años, la investigación sobre la integración europea experimentó una "revolución teórica" ${ }^{79}$ También se ha dicho que de los estudios de caso — por lo regular altamente

75 Edwards, Geoffrey y Spence, David, The European Commission, 2a. ed, Londres, Cartermill, 1997.

76 Lodge, Juliet, “The European Parliament from 'Assembly' to Co-Legislature: Changing the Institutional Dynamics", en Lodge, Juliet (ed.), The European Community and the Challenge of the Future, Londres, Pinter, 1989 y Rittberger, Berthold, "The creation and Empowerment of the European Parliament", Journal of Common Market Studies, vol. 41, núm. 2, 2003, pp. 203-225.

77 Alter, Karen J., "Who Are the Masters of the Treaty? European Governments and the European Court of Justice", International Organization, vol. 52, núm. 1, 1998, p. 121; también véase la obra de Stone Sweet, Alec, Governing with Judges: Constitutional Politics in Europe, Oxford, Oxford University Press, 2000.

78 Westlake, Martin y Galloway, David, The Council of the European Union, 3a. ed., Londres, John Harper, 2004.

79 McLean, Ian, "Two Analytical Narratives about the History of the EU", European Union Politics, vol. 4, núm. 4, 2003, p. 499. 
descriptivos y sin relación con las grandes preocupaciones de la ciencia política - se pasó a "una vibrante comunidad de investigación teóricamente pluralista que continúa atrayendo a nuevos adeptos". ${ }^{80}$ En esta sección se argumenta que lo anterior es sólo parcialmente cierto. Desde el anuncio del Plan Schuman, un puñado de pensadores planteó una serie de reflexiones teóricas sobre el fenómeno europeo. Su carácter innovador marcaría el rumbo de los estudios europeos y de los tres grandes debates actuales sobre la Unión Europea, mismos que tienen que ver con su forma de gobierno, su "déficit democrático" y su futuro.

El primero de estos debates divide a los que ven en el aparato institucional europeo rasgos ortodoxos y tratan de describirlo utilizando categorías y tipologías tradicionales, de los que consideran al gobierno europeo como una forma de organización política sin precedentes y urgen la construcción de nuevos marcos teórico-conceptuales. Entre los primeros destacan los que equiparan el caso europeo a un Estado de tipo federal. ${ }^{81}$ A diferencia, entre los segundos se encuentran los que tratan de explicar al aparato institucional europeo a través de modelos alternativos que suponen desde la "gobernación en múltiples niveles" 82 hasta la operación de una supranacionalidad que ha sido capaz de transformar significativamente la naturaleza misma del Estado westfaliano. ${ }^{83}$

80 Pahre, Robert, "Formal Theory and Case-Studies: Methods in EU studies", European Union Politics, vol. 6, núm. 1, 2005, p. 113.

81 Por ejemplo, Fisher, Joschka, "From Confederation to Federation: Thoughts on the Finality of European Integration", The Federal Trust for Education \& Research, European Essay, núm. 8, 2000; Nicolaïdis, Kalypso y Howse, Robert, The Federal Vision: Legitimacy and Levels of Governance in the United States and the European Union, Oxford, Oxford University Press, 2001; Heinenmann-Gruder, Andreas, Federalism Doomed? European Federalism Between Integration and Separation, Nueva York, Berghahn Books, 2002.

82 Bache, Ian y Flinders, Matthew (eds.), Multi-level Governance, Oxford, Oxford University Press, 2004 y Hooghe, Liesbet y Marks, Gary, Multi-level Governance and European Integration, Lanham, MD, Rowman \& Littlefield, 2001. Conviene indicar que este modelo fue originalmente desarrollado por Marks, Gary et al., "European Integration from the 1980s: State-Centric v. Multi Level Governance", Journal of Common Market Studies, vol. 34, núm. 3, 1996, pp. 341-378.

83 Tallberg, Jonas, European Governance and Supranational Institutions: Making States Comply, Londres, Routledge, 2003; Walker, Neil (ed.), Sovereignty in Transition, Oxford, Hart, 2003; Torres Espinosa, Eduardo, "El Estado-nación y la Unión Europea. ¿Hacia una necesaria reformulación de lo estatal”, Anuario Mexicano de Derecho Internacional, vol. VI, enero de 2006, pp. 551-575. 
Los orígenes de esta ya prolongada discusión se remontan a las primeras interpretaciones tanto del Plan Schuman como del Tratado de París. Como es fácil suponer, la mayoría de la literatura de entonces enfocó ambos eventos de acuerdo con la teoría de la soberanía dominante, sintetizada por la expresión: "la soberanía es indivisible... nada existe ni puede existir sobre el Estado". ${ }^{84}$ Ello explica sus reiteradas referencias al Estado-nación como "unidad básica del sistema europeo", su alta dosis de "positivismo legal", así como su silencio sobre los "desarrollos trasnacionales" en curso. ${ }^{85}$ Cabe indicar que la tendencia a encontrar paralelismo entre la primera Comunidad y las formas de Estado y de gobierno conocidas fue alentada por el propio Monnet al hablar de un "gobierno federal europeo". ${ }^{86}$

A contracorriente, las ideas seminales de una visión alternativa fueron también expresadas. La más importante de ellas fue subrayar que la característica distintiva de la nueva Comunidad era su carácter "supranacional", o "supernacional" en palabras de Van Raalte. ${ }^{87}$ Sobre la naturaleza de dicha Comunidad, un libro colectivo trató de determinar hasta qué punto su estructura se ajustaba a las categorías existentes, para concluir que constituía una unión de Estados sui generis ${ }^{88}$ En forma similar, Van Raalte concluyó que no era posible definir a esa Comunidad, ya que su Tratado constitutivo trajo "muchas cosas nuevas". En su opinión, la razón era que se trataba de "una nueva estructura en la frontera entre el derecho interno y el internacional", que exhibe signos de una evolución de "las relaciones inter-Estatales a relaciones Estatales super-nacionales". 89

84 Rosenstiel, Francis, Le principe de "supranationalité”, París, Éditions A. Pédone, 1962 , pp. 56 y 57.

85 Kaiser, Karl, "L'Europe des savants: European integration and the social sciences”, Journal of Common Market Studies, vol. 4, núm. 1, 1965, pp. 37-40.

86 Monnet, Jean, "The Silent Revolution in Europe", The New York Times Magazine, 3 de febrero de 1957, p. 50.

87 Van Raalte, Ernest, op. cit., nota 37, pp. 73 y 74 y 85; Kunz, Josef L., op. cit., nota 36, pp. 693 y 694; Reuter, Paul, La Communauté Européenne du Charbon et de l'Acier, París, Librairie Générale de Droit et de Jurisprudence R. Pichon et R. Durand-Auzias, 1953, pp. 140-143.

88 Grupo de Estudio del Instituto de Relaciones Internacionales de Bruselas, La Communauté Européenne du Charbon et de l'Acier, París, Librairie Armand Colin, 1953, p. 68.

89 Van Raalte, Ernest, op. cit., nota 37, pp. 73-74 y 85. 
De acuerdo con Vernon, el estudio del Tratado de París a partir de los "conceptos jurídicos familiares" empleados en su redacción, hace perder de vista su relevancia política, cuando ese Tratado "hace historia esencialmente porque da un paso más allá de esos conceptos tradicionales". ${ }^{90}$ Kunz fue más lejos al criticar los mismos cimientos teóricos y conceptuales del derecho internacional de su tiempo. Según el autor, para que éste pudiera ser considerado como verdadero derecho debería, "por necesidad, ser supranacional", esto es, derecho "sobre los Estados" y no "entre" ellos. De esta última concepción, añadió, se había derivado la noción tradicional de organización internacional, mientras que partiendo de la segunda debía construirse la noción de "lo supra-nacional" como "un principio de organización diferente". ${ }^{91}$

El segundo debate incorpora muy diversas visiones sobre el grado de democracia que exhibe el gobierno europeo o, utilizando el término de moda, sobre qué tan grande es su "déficit democrático". ${ }^{92}$ Esta discusión tampoco es nueva. Como se indicó antes, su origen se remonta a las negociaciones del Tratado de París y, en especial, a la reacción de los países del Benelux frente a la propuesta franco-alemana de crear un órgano supranacional con amplios poderes. ${ }^{93}$ Para aquellos países, la operación de la Alta Autoridad debía estar sujeta a un control democrático y este control debía ser ejercido por un órgano que representara a los Esta-

90 Vernon, Raymond, "The Schuman Plan: Sovereign Powers of the European Coal and Steel Community", The American Journal of International Law, vol. 47, núm. 2, 1953, p. 183.

91 Kunz, Josef L., op. cit., nota 36, pp. 693 y 694 (las cursivas son del texto original).

92 Véase, entre otros, a Cerny, Philip, "Globalization and the Erosion of Democracy”, European Journal of Political Research, vol. 36, núm. 1, 1999, pp. 1-26; Bergman, Torbjörn y Raunio, Tapio, "Parliaments and Policy-Making in the European Union”, en Richarson, Jeremy (ed.), op. cit., nota 67, pp. 117 y 118; Zweifel, Thomas D., Democratic deficit?: Institutions and regulation in the European Union, Switzerland and the United States, Lanham, MD, Lexington Books, 2002; y Hay, Colin, "Globalisation, 'EU-Isation' and the Space for Social Democratic Alternatives: Pessimism of the Intellect: a Reply to Coates", British Journal of Politics and International Relations, vol. 4, núm. 3, octubre de 2002, pp. 452-464.

93 Kersten, Albert, "A Welcome Surprise? The Netherlands and the Schuman Plan Negotiations", en Schwabe, Klaus (ed.), Die anfänge des Schuman Plans 1950/51-The Beginnings of the Schuman Plan, Nomos, Baden-Baden, 1988, pp. 295 y 296, y Spierenburg, Dirk y Poiderin, Raymond, op. cit., nota 52, pp. 15 y 16. 
dos miembros, así como por un tribunal de justicia. ${ }^{94}$ La trascendencia de este primer debate reside en que sin él "simplemente no habría habido una institución parlamentaria en el arreglo institucional inicial". ${ }^{95}$

Desde luego, el tema no estuvo ausente en el campo académico. Una de las posiciones más extremas fue la de Lavergne, quién criticó ácidamente al Plan Schuman por su intento de crear un "Super-Estado" dotado con "exorbitantes derechos e ilimitados poderes". ${ }^{96}$ Por su parte, Sanderson advirtió, visionariamente, en 1958, que en la medida en que la integración económica se extendiera a otros campos y las decisiones del órgano ejecutivo de la CECA "afecten aún más directamente la vida diaria de los ciudadanos de la Comunidad, la necesidad de un efectivo control democrático se hará más evidente". Este hecho, en su opinión, generaría presiones crecientes para constituir una "estructura política verdaderamente responsable ante un Parlamento Europeo electo directamente". ${ }^{97}$

El tercer y último debate discute el futuro de la Unión Europea vis-à-vis los dos eventos más recientes: el proyecto de una Constitución europea y la integración de doce nuevos países entre mayo de 2004 y enero de 2007. ${ }^{98}$ Aunque motivado por eventos coyunturales de muy diversas naturaleza, el asunto del futuro del proceso europeo de integración ha estado también en las agendas política y académica desde el Plan

94 Ibidem, pp. 296 y 297.

95 Rittberger, Berthold, op. cit., nota 30, pp. 701 y 702 (la cita está en cursivas en el texto original).

96 Lavergne, Bernard, Les Plan Schuman: Exposé et Critique de sa Portée Économique et Politique, París, Presses Universitaires de France, 1951. En especial, los capítulos III, V y VI.

97 Sanderson, Fred H., op. cit., nota 54, p. 200.

98 Entre los libros más recientes que abordan el primer tema se encuentran: Van Gerven, Walter, The European Union. A Polity of States and Peoples, Oxford, Hart, 2005; Milton, Guy, Keller-Noellet, Jacques y Bartol-Saurel, Agnieszka, The European Constitution: Its Origins, Negotiation and Meaning, Londres, John Harper, 2005; y Dony, Michael y Bribosia, Emmanuelle (eds.), Commentaire de la Constitution de l'Union Européenne, Bruselas, Editions de l'Université de Bruxelles, 2005. Sobre el segundo tema, véase Verdun, Amy y Croci, Osvaldo (eds.), The European Union in the Wake of Eastern Enlargement: Institutional and Policy-Making Challenges, Manchester-Nueva York, Manchester University Press, 2005; Schimmelfennig, Frank y Sedelmeier, Ulrich (eds.), The Europeanization of Central and Eastern Europe, Nueva York, Ithaca, Cornell University Press, 2005, y Sasse, Gwendolyn y Gordon, Claire, Europeanization and Regionalization in the EU's Enlargement to Central and Eastern Europe: The Myth of Conditionality, Houndsmills, Reino Unido, Palgrave Macmillan, 2004. 
Schuman. Parker, por ejemplo, realizó en 1952 uno de los primeros ejercicios de prospectiva. Para este observador estadounidense, los beneficios económicos de dicho Plan se veían "remotos", y sus ganancias políticas "insignificantes", simplemente porque "las esperanzas de prosperidad, paz y seguridad" en Europa no podían descansar en "un plan abstracto", ni en "meros ideales" de libre comercio y unidad política. ${ }^{99}$

Aun antes del inicio de la historia, Kunz planteó dos escenarios extremos: "Si la nueva Comunidad y sus órganos nacen y trabajan... es probable que ello conduzca a nuevos antagonismos o, como todos esperamos, a la unión mucho mas íntima de esta parte de Europa". ${ }^{100}$ Ya creada la nueva Comunidad, Mendershausen concluyó que constituía "uno de los grandes logros organizacionales en el mundo Occidental desde la guerra", por lo que "nos hace esperar el día siguiente con una mayor esperanza, pero eso no garantiza un futuro libre de problemas. ${ }^{101}$ Para Vernon era aún muy pronto para afirmar que "los nuevos conceptos de soberanía" del Tratado de París "representan el inicio de una tendencia". Esto dependerá, según el autor, de la interpretación que de ellos hagan los órganos de la Comunidad, así como de que los seis países signatarios decidan aceptar o no la "nueva residencia de soberanía". ${ }^{102}$

En suma, el proceso europeo de integración ha sido interpretado lo mismo por escépticos que por creyentes, por detractores que por defensores, por pesimistas que por optimistas, por prácticos que por teóricos, por teóricos de la elección racional que por institucionalistas, por ortodoxos que por heterodoxos. El hecho es que la Unión Europea y su incuestionable supranacionalidad seguirán invitando a la reflexión y contribuyendo, así, al enriquecimiento de las ciencias sociales, tal como ocurrió con motivo de la creación de la Comunidad Europea del Carbón y del Acero.

\section{CONCLUSIONES}

Este artículo ha mostrado que la actual Unión Europea no podría entenderse sin la Comunidad Europea del Carbón y el Acero, y que, a su vez, para entender el nacimiento de esta última es necesario tener presen-

99 Parker, William N., op. cit., nota 39, pp. 393 y 395.

100 Kunz, Josef L., op. cit., nota 36, p. 698.

101 Mendershausen, Horst, op. cit., nota 44, p. 287.

102 Vernon, Raymond, op. cit., nota 90, p. 183. 
te la histórica rivalidad franco-alemana. El desenlace de la Segunda Guerra permitió a Francia utilizar, nuevamente, su carácter de aliado para tratar de construir una Europa más segura para ese país. El cómo lograrlo vendría de Monnet a la cabeza de un puñado de franceses. En retrospectiva, su estrategia parece demasiado simple por su lógica: Si un país es capaz de "fusionar" el patrimonio de su enemigo con el propio, la rivalidad se convertirá en cooperación mutua. Pero, su gran innovación reside en que para lograrlo era indispensable crear instituciones con autoridad política y jurídica real sobre las partes, no sólo entre ellas.

El arreglo institucional cuatripartita dado a la nueva Comunidad es producto de las negociaciones del Tratado de París y sus rasgos supranacionales tienen dos fuentes. Por un lado, la propuesta francesa de constituir una Alta Autoridad con amplios poderes sobre las partes y, por el otro, la insistencia de los países del Benelux en la necesidad de incorporar otras instituciones que controlaran la acción de la primera. Como quedó debidamente sustentado, el arreglo elegido mostró muy pronto tanto viabilidad como eficacia y eficiencia para alcanzar sus fines. De mayor relevancia aún es el hecho de que las características estructurales, operativas y teleológicas básicas con las que fue concebido hayan sobrevivido al paso del tiempo y, además, evolucionado en la dirección deseada por sus diseñadores.

Otra conclusión del trabajo es que esta inusual continuidad es resultado de la decisión colegiada de incorporar el "principio de supranacionalidad" en la estrategia de integración, no de la voluntad individual de los actores y menos del azar. A este hecho contribuyeron, principalmente, dos factores. Por un lado, las condiciones favorables para una transferencia real de soberanía nacional a una instancia relativamente independiente de mayor jerarquía generadas por la posguerra. Y, por el otro lado, la gradualidad con la que esa revolucionaria transferencia de poder fue pensada. A partir de una modesta integración económica sectorial se avanzaría en la medida de lo deseable, pero sobre todo de lo posible, hacia la construcción de una ideal "Comunidad Política Europea".

En lo general, el artículo confirma los supuestos generales de todos los enfoques institucionales actuales: 1) Una vez consolidadas, las nuevas instituciones adquieren una personalidad y una dinámica diferente a las de los actores individuales sujetos a sus reglas de juego; 2) Las instituciones son importantes, precisamente, porque son capaces de moldear la acción política de esos actores; 3) Las instituciones se transforman, 
pero siempre de manera gradual; y, 4) Los factores contextuales son el principal motor del cambio institucional. ${ }^{103}$ Sin embargo, las similitudes entre los primeros y últimos debates en torno al caso europeo sugieren que permanecen sin respuesta muchas de las interrogantes originalmente planteadas. En especial, la correspondiente a la naturaleza e implicaciones del "principio de supranacionalidad".

Una causa de lo anterior ha sido la gran dinámica del proceso europeo de integración, misma que ha tendido a favorecer el análisis de coyuntura sobre la construcción teórica. Sin embargo, la causa de fondo fue identificada por Vernon desde 1953, al indicar que no se puede interpretar un fenómeno sin precedentes, utilizando marcos teórico-conceptuales convencionales. En cualquier caso, y sin pretender cuestionar los innegables y sustanciales avances logrados en esta materia, el hecho es que la Comunidad Europea del Carbón y del Acero - convertida ya en una madura Unión Europea - continúa su marcha financiada por el euro, enarbolando una bandera de doce estrellas y tarareando la Novena Sinfonía de Beethoven.

103 Vergara, Rodolfo, "Estudio introductorio", en March, James G. y Olsen, Johan P., El redescubrimiento de las instituciones, México, Colegio Nacional de Ciencia Política y Administración Pública-Fondo de Cultura Económica, 1997, pp. 25-29; Peters, Guy B., op. cit., nota 1 . 